\title{
CRÍTICA E RENOVAÇÃO DA EDUCAÇÃO FÍSICA COLOMBIANA: UMA COMPARAÇÃO COM O BRASIL
}

\author{
CRITIQUE AND REINVENTION OF COLOMBIAN PHYSICAL \\ EDUCATION: A COMPARISON WITH BRAZIL C P
}

CRÍTICA Y RENOVACIÓN DE LA EDUCACIÓN FÍSICA COLOMBIANA: UNA COMPARACIÓN CON BRASIL C P

doi' https://doi.org/10.22456/1982-8918.105572

(D) Karen Lorena Gil Eusse* <kalogil@yahoo.es>

Felipe Quintão Almeida*<fqalmeida@hotmail.com>

Valter Bracht* <vbracht13@gmail.com>

*Universidade Federal do Espírito Santo. Vitória, ES, Brasil.

Resumo: O artigo analisa um movimento de crítica e renovação da Educação Física colombiana a partir das últimas décadas do século XX, comparando-o com fenômeno similar no Brasil. Metodologicamente, está fundamentado, de um lado, na análise de conteúdo de dois periódicos colombianos e em 16 entrevistas com profissionais da Educação Física daquele país. De outro lado, baseia-se na farta literatura dedicada ao tema no Brasil. A reflexão comparada demonstra as consequências diversas do processo de esportivização e cientifização do componente curricular, oportunidade para identificar semelhanças, diferenças, continuidades, rupturas, mas, também, as renovações epistemológicas produzidas na Educação Física dos dois países.

Palavras chave: Esportes. Ciência. Brasil. Colômbia.
Recebido em: 21 jul. 2020 Aprovado em: 23 nov. 2020 Publicado em: 18 fev. 2021

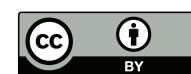

Este é um artigo publicado sob a licença Creative Commons Atribuição 4.0 Internacional (CC BY 4.0).

eISSN: $1982-8918$ 


\section{INTRODUÇÃO}

Este artigo analisa a experiência de crítica e renovação da Educação Física na Colômbia a partir do último terço do século $X X$, comparando-a com semelhante fenômeno no Brasil. Trata-se de uma oportunidade para identificar semelhanças, diferenças, permanências e rupturas em busca dos sentidos dos processos educacionais nas realidades investigadas. Suas observações estão inseridas no âmbito de uma tese de doutorado recém-concluída (EUSSE, 2020), cujo objetivo foi discutir a crítica produzida, já a partir do final dos anos 1960, à crescente esportivização e cientifização da Educação Física no país andino. Este processo teria resultado numa renovação da disciplina, com implicações epistemológicas, curriculares e políticas diversas.

Para fundamentar as reflexões aí produzidas, duas estratégias metodológicas foram assumidas nesta pesquisa de caráter qualitativo. De um lado, e inspirado nas considerações de Bardin (2011) a respeito da análise de conteúdo, realizouse o estudo das duas mais importantes revistas acadêmicas da Educação Física colombiana: Educación Física y Deporte (1979-2016) e Lúdica Pedagógica (19912017). Entre os critérios para a adoção de ambas, é possível elencar o fato de terem um ciclo de vida longevo, o que permitiu a elas registrar os modos de funcionamento do campo nas últimas décadas, veiculando discussões, problematizações e polêmicas privilegiadas por seus intelectuais. Além disso, aqueles periódicos estão disponíveis gratuitamente em plataformas digitais, o que facilitou a consulta de seus números. Considerando os objetivos da tese, realizou-se uma pré-análise de Educación Física y Deporte e Lúdica Pedagógica por meio da leitura de todos os títulos e resumos publicados. Uma segunda exploração do material permitiu excluir aqueles artigos que não se adequavam ao escopo, o que resultou na eleição de 208 artigos de Educación Física y Deporte e 124 textos de Lúdica Pedagógica. Estes textos foram lidos integralmente, ocasião que permitiu organizar e interpretar seu conteúdo. Além dos dois impressos, a investigação também se construiu em torno da realização de 16 entrevistas com professores que tomaram parte, de distintos modos, no processo de crítica e renovação da disciplina na Colômbia. ${ }^{1}$

A comparação da experiência colombiana com a brasileira, neste artigo, é feita com base em estudos prévios (BRACHT et al., 2011, 2012; ALMEIDA; BRACHT; VAZ, 2015), bem como na considerável literatura destinada a compreender a crise/ crítica identitária desencadeada por um "movimento renovador" da disciplina.

O texto está organizado em uma única sessão, que é seguida das considerações finais.

\section{A EDUCAÇÃO FÍSICA NO BRASIL E NA COLÔMBIA}

Colômbia e Brasil compartilham, a despeito de suas singularidades, percursos semelhantes em relação à Educação Física. Não muito diferente do que aconteceu em outros países da América Latina, ambos reproduziram um modelo formativo,

1 Neste artigo essa fonte não será mobilizada. Por isso, informações sobre os docentes podem ser consultadas na supracitada tese. 
importado da Europa, baseado na ginástica pedagogizada, mas que foi, ao longo do século XX, lenta e inexoravelmente suplantado por um modelo técnico-esportivo. Em termos temporais, essa alteração de sentido, nos dois lugares, tem nos anos 1970 um ponto de inflexão, com uma série de iniciativas que resultaram na esportivização do componente curricular. Essa tendência, por sua vez, foi alimentada por políticas que, nos dois países, favoreceram a atividade científica nos respectivos campos acadêmicos.

Apesar de a esportivização e a cientifização² serem fenômenos provocados por múltiplas causas, merece destaque, nos termos da comparação pretendida, a influência exercida por convênios assinados por Brasil e Colômbia com a República Federal da Alemanha, em especial com a Escola Superior de Esportes de Colônia. Na Colômbia, esse acordo ficou conhecido como "Convênio Colombo-Alemão", experiência investigativa e docente baseada em cinco metas principais:

a. investigación del curriculum, la didáctica y la metodología de la Educación Física, el deporte y la recreación; b. información y documentación de la Educación Física, el deporte y la recreación; c. medicina del deporte; d. enseñanza del movimiento y del entrenamiento; e. organización del deporte (PINILLOS, 2003, p. 148).

Isso possibilitou, durante uma década (1974-1984), a criação da revista Educación Física y Deporte, a tradução de bibliografia estrangeira, o incentivo à pesquisa e a ida de colombianos à Alemanha para aperfeiçoamento, bem como a presença de professores alemães nas Universidades de Antioquia (em Medellín) e Valle (em Cáli), já que o convênio não prosperou em Bogotá (como inicialmente previsto). Esperava-se, além disso, que o conceito de "Ciência do Esporte" pudesse ser a referência norteadora da área acadêmica na Colômbia, o que acabou não se efetivando (EUSSE, 2020).

No caso do Brasil, a parceria foi possível graças ao Convênio de Assistência Técnica Brasil/Alemanha, no qual se inseria o projeto "IntercâmbioTécnico Internacional relacionado à Educação Física e Desportos" (1963-1982), que permitiu intercâmbios científicos entre brasileiros e alemães, resultando na estruturação da pesquisa, na aquisição de equipamento didático e tecnológico, na abertura de laboratórios, no apoio financeiro, na oferta de cursos técnicos, na publicação/tradução de livros ${ }^{3}$ e, mesmo, impactou na elaboração do "Plano Nacional de Educação Física e Desporto" (PNED), de 1976 (SANTOS, 2017). É nesse contexto em que se situa a participação alemã na criação, em 1977, do primeiro curso de mestrado em Educação Física da América do Sul, na Universidade de São Paulo (AMADIO, 2017); dois anos depois, criou-se o mestrado em Ciência do Movimento Humano, da Universidade Federal de Santa Maria (ROSA, 2017). Os dois programas tiveram contribuição decisiva do acordo técnico que o Brasil tinha estabelecido com a Alemanha.

\footnotetext{
2 Por "esportivização", entende-se, de um lado, a transformação do esporte no conteúdo hegemônico da Educação Física Escolar. De outro, significou a colonização da Educação Física por princípios/códigos que são próprios ao fenômeno esportivo. Por "cientifização", compreende-se o processo multicausal que resultou no incremento da atividade científica na área.

3 A "Coleção Educação Física", da editora brasileira "Ao livro-técnico", publicou, entre os finais das décadas 1970 e 1980, 22 livros escritos por professores alemães. O coordenador da referida coleção era Jürgen Dieckert, professor visitante da Universidade Federal de Santa Maria. Na Colômbia, o convênio, em parceria com o Ministerio de Educación Nacional, publicou, em 1973 e 1974, três guias curriculares para os professores de Educação Física na escola primária. O alemão Heimo Ulmer foi o assessor técnico do convênio nas três edições.
} 
Outro ponto passível de comparação é o debate que se produziu, nos dois países, a respeito dos esforços para se instaurar uma tradição disciplinar que seria fortemente marcada pelo esporte e pela atividade científica. No Brasil, há farta literatura dedicada a isso e à crise epistemológica instaurada. Oliveira (2001) evidenciou, a respeito do binômio esporte e ciência, as tensões e a falta de consenso nas páginas da Revista Brasileira de Educação Física e Desportos (1968-1984), periódico "oficial" da Divisão de Educação Física do Ministério da Educação durante o regime militar. Mais tarde, nos anos 1980, essas dissensões foram fortalecidas com uma crítica radical da própria disciplina no contexto de uma sociedade em conflito, em luta pela redemocratização. Em retrospectiva, identifica-se essa crítica a um "movimento renovador" (MACHADO, 2012) que, inspirado em um referencial crítico, especialmente o marxista, censurou a transformação da Educação Física em treino esportivo e a cientifização crescente. Esse quadro provocou uma reflexão sobre a identidade epistemológica da disciplina com repercussões curriculares e pedagógicas diversas no país.

Na Colômbia, a tradição esportivista também não progrediu sem conflito. No estudo das fontes mobilizadas na tese de doutorado, identificou-se que múltiplas vozes posicionaram-se com desconfiança em relação a essa tendência. Uma delas ecoa o posicionamento de professores alemães envolvidos com o "Convênio ColomboAlemão", pois muitos deles foram críticos das tentativas de esportivizar a disciplina. Talvez tenha sido o alemão Herman Gall, ${ }^{4}$ um dos diretores do referido "Convênio", o que melhor representou os argumentos instaurados em favor de um trato pedagógico, didático e humanístico da prática esportiva nas aulas de Educação Física.

De igual maneira, também no Brasil, destacou-se a presença de alemães preocupados com a dimensão didática, pedagógica e humanística do ensino do esporte. Além do supracitado Jürgen Dieckert, deve-se mencionar Reiner Hildebrandt, ${ }^{5}$ autor, com Ralf Langing, de um livro que se tornaria muito conhecido no país: Concepções abertas no ensino de Educação Física (HILDEBRANDT; LANGING, 1986). Rosa (2017), referindo-se à presença alemã na Universidade de Santa Maria, relata as tensões produzidas na instituição pelo fato de alguns professores alemães operarem com saberes e práticas que estavam relacionados a um viés didático e pedagógico do esporte baseado nas Ciências Humanas e Sociais, contrariando, assim, as proposições dominantes naquela instituição, então fundamentadas nos saberes da psicologia do esporte, da biomecânica e da fisiologia do esporte.

Os alemães, todavia, não foram os únicos a discutirem os perigos reducionistas que poderiam advir (e que, de fato, resultaram) da esportivização. Há, por assim dizer, outros processos que precisam ser considerados na Colômbia. Um deles resulta do intercâmbio que o país estabeleceu com Cuba. Isso levou à ilha caribenha, a partir do final dos anos 1970, muitos profissionais de Educação Física para aperfeiçoamento técnico. Essa experiência impactou a Educação Física colombiana de modo ambíguo, pois ao mesmo tempo em que colocou em contato muitos professores com uma Educação Física esportivista, possibilitou experiências

4 Sobre a atuação de Gall no "Convênio Colombo-Alemão" e a participação alemã no debate a respeito da esportivização, conferir (EUSSE; ALMEIDA; BRACHT, 2018, 2019a, 2019b).

5 Foi professor visitante na Universidade Federal de Santa Maria. 
que contribuíram para a crítica a essa tradição. Entre essas experiências podem-se destacar: a) o acesso à literatura oriunda de países comunistas, como a Alemanha Oriental e o bloco soviético, o que permitiu que bibliografia inédita fosse consumida na Colômbia. Destaque absoluto, quanto a isso, ao livro, de Kurt Meinel, Didáctica del movimiento: ensayo de una teoría del movimiento en el deporte desde el punto de vista pedagógico e Teoría Pedagógica de la Educación Física, de Ommo Gruppe. b) O conceito de Cultura Física, utilizado em Cuba, passou a ser considerado como uma possibilidade de organizar a área na Colômbia, uma alternativa, assim, à Ciência do Esporte. c) E, talvez mais importante, o contato com Cuba politizou professores de Educação Física, seduzindo muitos docentes aos ideais do comunismo e alimentando um desejo de revolução social que já estava espraiado na sociedade colombiana nos anos 1970. Esses aspectos, conjugados, também favoreceram uma leitura crítica a respeito da crescente esportivização da disciplina.

No movimento estudantil, também se pode encontrar mais resistências à esportivização. Segundo Vaca (1998) e Wilches (2012), a década de 1970 foi caracterizada por intensa movimentação estudantil e política nas universidades colombianas. Vozes importantes do movimento pertenciam ao curso de Educação Física, "[...] fueron aguerridos activistas, participando con los demás universitarios en verdaderos conciertos de piedra [...]" (VACA, 1998, p. 88). Os estudantes, nas universidades, protestaram por questões relacionadas aos problemas sociais do país, mas também por temas próprios da Educação Física, como a Tecnologia Educativa e o currículo técnico-esportivo que caracterizava a Educação Física nas instituições formadoras. Ao mesmo tempo, tinham uma forte preocupação com o papel social da disciplina e com a "intervenção estrangeira" manifesta, por exemplo, em convênios e acordos de cooperação (invariavelmente, aliás, o "Convênio Colombo-Alemão" foi alvo de protesto estudantil). A formação política recebida estava baseada em um discurso marxista que relacionava o esporte com a força invasiva do capitalismo. Em seu lugar, o que os estudantes almejavam era uma Educação Física revolucionária, interessada na transformação de uma sociedade em ebulição. ${ }^{6}$

O movimento estudantil, por sua vez, estava articulado, em essência e conteúdo, com o movimento dos professores. Nesse contexto, destacam-se o Movimento Pedagógico Nacional e a Associação Colombiana de Professores de Educação Física. Preocupados com a situação social do país e com a ação da Tecnologia Educativa na educação e, ao mesmo tempo, reivindicando o papel do professor na transformação da sociedade e na valorização da produção cultural própria à Colômbia, esses movimentos geraram as condições de possibilidade para reunir profissionais do campo no debate acadêmico crítico, no caminho da "reconstrução da Educação Física". Chinchilla (1989, p. 57), na condição de presidente da Associação Colombiana de Professores de Educação Física, apontou alguns dos problemas que atravessavam os profissionais da disciplina e que eram matéria de problematização nos anos 1980. Segundo ele (1989, p. 57), o professor de Educação Física estava imerso em "[...] una práctica centrada en lo técnico, una posición política indiferente,

6 Não se pode esquecer, neste contexto, a influência das guerrilhas na intelectualidade acadêmica colombiana Entre eles, os estudantes (ACEVEDO; GONZÁLEZ, 2011). Muitos desses discentes viriam a se tornar, anos depois, professores nas instituições formadoras de Educação Física. 
una dificultad para integrar su trabajo a un proyecto social y una subestimación para generar y enfrentar posiciones de liderazgo y dirección pública y académica". Pode se ver, nessa denúncia, o chamado a "Una reforma acadêmico profesional que transforme la Educacion Física” (CHINCHILLA, 1989).

Todo o debate provocado por esses intercâmbios e movimentos sociais de caráter político-ideológico foi acompanhado de uma intensa produção acadêmica divulgada nas páginas das duas principais revistas da Educação Física colombiana naquele contexto: Educación Física y Deporte e Lúdica Pedagógica. A análise desses periódicos, no âmbito da tese que sustenta os argumentos neste artigo, permite concluir que se desenvolveu, sobretudo a partir da década de 1980, uma preocupação com as características "problemáticas" do esporte na educação dos sujeitos. No geral, por meio de uma leitura crítica que enfatizava aspectos negativos da prática, os autores entendiam que o fenômeno deveria ser transformado pedagogicamente para que sua presença se justificasse nas aulas de Educação Física (um esporte "da" escola), enfatizando um ensino do esporte que aplacasse o que consideravam como características perversas de sua prática, como a competição a todo custo, a sobrepujança do adversário, a busca do recorde, a compreensão do corpo como máquina, práticas centradas na repetição, desligadas do desfrute lúdico e que privilegiavam um grupo limitado de alunos, etc. No extremo, até houve aqueles que advogaram em favor da ausência do esporte nas aulas de Educação Física, ${ }^{7}$ valorizando, ao contrário, manifestações corporais não hegemônicas ou baseadas nas manifestações de movimento que seriam mais afeitas à realidade colombiana. ${ }^{8}$ Toda essa reflexão precisa ser situada no âmbito dos debates críticos a respeito da esportivização da Educação Física.

A análise do que se passou na Educação Física colombiana permite identificar muitas similitudes com o caso brasileiro. É nos anos 1980, em função de um contexto político-econômico muito particular em cada uma das realidades, que se radicaliza uma crítica contra a tradição esportivista da disciplina, manifesta, especialmente, no que se costuma chamar de Tecnicismo Educacional ou Tecnologia Educativa. Há semelhança, também, quanto à necessidade de transformar o esporte nas aulas de Educação Física, conferindo a ele uma dimensão pedagógica crítica e, por assim dizer, "humanista" que seja mais afeita aos códigos escolares. Também salta aos olhos a importância da perspectiva marxista na crítica realizada, embora as fontes dessa influência nem sempre coincidam. Por exemplo, em relação ao Brasil, a revolução cubana não teve um impacto digno de nota na formação do chamado "movimento renovador" da Educação Física. Não se deve negligenciar, também, a participação do movimento estudantil e das Associações de Professores de Educação Física/Federação Brasileira das Associações de Professores de Educação Física, cujos congressos, durante os anos 1980 e 1990, foram "palco" para debates críticos. Um caso à parte, nesse contexto, é o Colégio Brasileiro de Ciências do Esporte, instituição fundamental na crítica instituída ao esportivismo.

7 Este foi o caso de Carlos Bolívar, um dos principais críticos, nos anos 1980, da esportivização da Educação Física colombiana e ferrenho defensor da dimensão pedagógica da disciplina.

8 Oliveira (2001) também mostra, em relação ao Brasil, como essa necessidade de preservar a pluralidade das práticas corporais das mais diversas origens culturais ecoou nas páginas da Revista Brasileira de Educação Física e Desportos. 
A crítica ao esporte, por sua vez, deve ser compreendida no âmbito do já aludido processo de cientifização da Educação Física. No que diz respeito a isso, não há dúvida de que a necessidade de cientificizar a disciplina foi um legado central do "Convênio" para a Colômbia e para o Brasil". Era consenso entre os profissionais alemães que a Educação Física, na Colômbia, era pouco científica, baseada em uma prática espontaneísta e pouco racional. Seria preciso, então, transformá-la, dotando-a de uma nova legitimidade acadêmica e de um inédito reconhecimento social. ${ }^{10}$ Nesse âmbito, e como o grupo de alemães que chegou à Colômbia era plural, ${ }^{11}$ "versado" nas muitas subdisciplinas da Ciência do Esporte, a ciência que se praticou no "Convênio Colombo-Alemão" aflorou nas mais diversas perspectivas das Ciências Naturais e Humanas, possibilitando um terreno fértil para o debate de ideias a respeito do que significaria fazer da Educação Física uma prática mais científica.

Neste contexto, não se deve rotular, pura e simplesmente, os "esforços alemães" de positivistas, nem mesmo resumir suas propostas à compreensão que a literatura convencionou chamar de tecnicista. Ao contrário, muitos deles foram também críticos desses reducionismos e dos riscos provocados pela inflação de um modo de se praticar a ciência que desconsidera as especificidades de outro. Esse reconhecimento é importante, pois, ainda hoje, é possível encontrar, tanto na literatura da área como no depoimento de alguns entrevistados, a interpretação segundo a qual o legado do "Convênio" para a Colômbia foi a esportivização e a cientifização, desconsiderando, assim, a contribuição dos seus profissionais na crítica a essas tendências.

Apesar dessa ressalva, a análise das duas revistas supracitadas e o conteúdo das entrevistas realizadas evidenciam que, ao final, o esforço interdisciplinar do "Convênio" havia fracassado graças ao predomínio de uma concepção de ciência que a crítica caracterizaria como positivista, o que teria fortalecido práticas esportivistas na formação em Educação Física. Como alternativa a essa situação, fortemente se colocou a necessidade de uma ruptura com o paradigma biologicista e instrumental na prática pedagógica da disciplina. O corte epistemológico pretendido, diga-se de passagem, foi acompanhado e/ou possibilitado pela presença, cada vez maior, dos aportes críticos oferecidos pelas Ciências Humanas e Sociais e pela Filosofia.

Esta necessidade de mudança é similar ao que teria acontecido na Educação Física brasileira a partir dos anos 1980. A história dos programas de pós-graduação em Educação Física demonstra que acabou prevalecendo a perspectiva "biodinâmica" de ciência. As lutas que se estabeleceram, nos anos 1980, no âmbito do Colégio Brasileiro de Ciências do Esporte, também encontraram parte de sua motivação na crítica a esse modo de fazer ciência (PAIVA, 1994), que se tornou hegemônico

\footnotetext{
9 No Brasil, a necessidade de cientificizar a área foi uma das conclusões do diagnóstico de 1969/70 (COSTA, 1971). 10 A título de comparação com o que se experimentou no Brasil, vale a pena reproduzir o que foi escrito em um dos editoriais da recém-inaugurada Revista Brasileira de Ciências do Esporte: "Do mesmo modo, o professor de Educação Física, não pode mais ser representado como o homem forte e de boa vontade que 'distraia' os alunos entre as aulas de biologia e matemática. [...] Hoje ele deve associar e seu cronômetro ao trabalho de laboratório de fisiologia do exercício; hoje, é ele responsável pelo surgimento de atletas e pelo desenvolvimento de suas potencialidades; em resumo, hoje ele não é mais o 'professor de ginástica', mas o mestre em ciências do esporte. [...] É a ciência do esporte ganhando corpo, fazendo alma, adquirindo consciência e consistência” (EDITORIAL, v. 2, n. 2, 1981).

11 Este é um fato também verificado na realidade brasileira (AMADIO, 2017; SANTOS, 2017; ROSA, 2017).
} 
na área e que ainda repercute na atualidade (MANOEL; CARVALHO, 2011). ${ }^{12}$ De igual maneira, intensificaram-se, no campo brasileiro, as críticas ao paradigma biomédico, alimentadas por reflexões baseadas no conteúdo das "humanidades" e com expectativa de repedagogizar uma prática que havia se tornado instrumental graças à esportivização e à cientifização.

O incremento da atividade científica nos dois países em comparação, com vistas a suplantar o déficit de ciência no campo, também permitiu um intenso debate a respeito da identidade disciplinar e profissional. De maneira muito similar ao que se sucedeu no Brasil (BRACHT, 1999), também na Colômbia os anos 1980 foram pródigos na reflexão epistemológica sobre os "fundamentos" da Educação Física, com implicações diversas na formação profissional e na prática pedagógica. Quem formamos? Para que formamos? Qual é nossa identidade? Como deveríamos formar? Qual relação estabelecer com a ciência? A citação abaixo, de Gall (1980, p. 2), expressa essas preocupações:

[...] por qué debe existir una formación de educadores físicos en las universidades? ¿para qué fin deben formarse los educadores físicos? ¿qué tareas básicamente deben llenar más tarde los profesores de Educación Física? [...] ¿Qué conocimientos y destrezas debe poseer el profesor de Educación Física?, es decir, básicamente ¿sobre qué contenidos debe ser adiestrado, qué habilidades debe dominar en su profesión? Expresado de manera muy burda ¿él debe ser un paquete de músculos sin nada en la cabeza, o un científico del entrenamiento adiestrado en laboratorios? ¿Debe ser más bien un buen jugador de fútbol o nadador o debe ser más un profesor con bases pedagógicas y psicológicas? (GALL, 1980, p. 2).

Neste contexto, "[...] la esencia del problema sigue siendo la misma: Qué identifica y distingue profesionalmente a nuestro gremio? Qué es Educación Física? Cuáles son sus propósitos específicos?" (BOLÍVAR, 1988, p. 11). O enfrentamento dessas questões poderia contribuir para a elaboração de "[...] un cuerpo teórico organizado y estructurado por un lenguaje científico" (BOLíVAR, 1991).

Nestas circunstâncias, destacou-se a reflexão sobre o objeto de estudo da disciplina. Tomando em retrospectiva o debate reproduzido nas páginas dos impressos estudados na tese de doutorado, algumas alternativas foram encontradas na sua definição. Ainda nos anos 1980, o "movimento" foi "eleito", na Colômbia, como objeto de estudo da Educação Física, mesmo que não houvesse concordância quanto à abordagem que o definiria, já que autores diversos foram utilizados para fundamentar o movimento como objeto (Kurt Meinel, José Maria Cagigal, Jean Le Boulch, etc.). As fontes estudadas demonstram não apenas os usos que se fizeram das ideias desses autores no país, mas alguns tiveram a oportunidade de estar na Colômbia para visitas técnicas e cursos. Esse foi o caso de Cagigal, que esteve mais de uma vez na Universidad Pedagógica Nacional e é reconhecido como um dos mais influentes pensadores naquela instituição nos anos 1980 (FACULTAD, 2002; WILCHES, 2012). Também nessa universidade deve-se reconhecer a centralidade da psicomotricidade na formação de seus quadros, especialmente graças à influência que, desde os anos 1970, a psicocinética de Le Boulch exerceu em docentes da "casa", como Hector Peralta e María Teresa Velázquez, frequentadores, aliás, dos cursos de Le Boulch.

12 Situação, aliás, semelhante à da Colômbia (URREGO, 2014). 
Outras expressões, nas décadas seguintes, foram introduzidas para referir-se ao objeto de estudo da Educação Física, o que acabou provocando uma profusão de maneiras e modos de se referir à profissão e ao campo acadêmico. Sem perder de vista o impacto de perspectivas internacionais na Colômbia, merece destaque a Ciência da ação motriz (praxiologia motriz), de Pierre Parlebas (conduta motriz como objeto), e a Ciência da Motricidade Humana, de Manuel Sérgio (motricidade humana como objeto).

Como resultado dessa influência internacional e do debate que provocou, na própria Colômbia, começaram a surgir, já a partir dos anos 1990, propostas para caracterizar uma nova identidade do campo acadêmico. Vale ressaltar, por sua relevância e abrangência, os conceitos de expresiones motrices e educación corporal, ambos desenvolvidos por professoras da Universidad de Antioquia (respectivamente, Rubiela Arboleda e Luz Elena Gallo). Às duas terminologias poder-se-ia juntar a perspectiva da experiencia corporal, concepção entendida como objeto de estudo da Educação Física no âmbito da Licenciatura em Educação Física da Universidad Pedagógica Nacional.

A presença daqueles autores e o surgimento de novas orientações permitiram um contraponto renovador às tendências esportivizantes da Educação Física e ofereceram, ao mesmo tempo, outros olhares sobre a atividade científica, não restritos ao que ficou classicamente conhecido como positivismo/tecnicismo.

Ao longo dos anos, todavia, a necessidade de encontrar, por meio de um recorte na realidade inerte, um "objeto" para caracterizar a área não foi suprida. Expressão desse fracasso, que se estende à atualidade, é a diversidade de nomes/conceitos identificados nas páginas das duas revistas estudadas para referir-se à identidade e/ou ao objeto da Educação Física, um quadro que repercute na educação superior, cujos programas têm se orientado a partir de diversas compreensões: do "ser humano em movimento" passando pelas expresiones motrices até a "atividade física".

No Brasil, Kurt Meinel não teve suas ideias extensivamente consideradas, embora seja reconhecido por sua contribuição no seu país de origem. Jean Le Boulch, José Maria Cagigal, Pierre Parlebas e Manuel Sérgio foram mais "consumidos" e ecoaram, em maior ou menor medida, em revistas e nas produções de autores brasileiros. ${ }^{13}$ Com exceção do último, com sua proposição a respeito de uma Ciência da Motricidade Humana, não foram seriamente considerados nas tentativas de a disciplina solucionar sua crise de identidade nos anos 1980. Isso vale, ao menos, no âmbito das iniciativas do que se costuma chamar, no país, de "movimento renovador" da Educação Física. A defesa do movimento como objeto de estudo da Educação Física também veio à tona no âmbito de vertentes marcadamente cientificistas, como a Ciência do Movimento Humano e a Cinesiologia. Ao mesmo tempo, nos dois países, difundiu-se o argumento de que a identidade da área deveria ser construída em torno da dimensão pedagógica da disciplina e não com base na construção de uma nova ciência. Esse princípio manifesta-se, no Brasil, nos conceitos empregados para referir-

13 Uma curiosidade: diferente do que se passou na Colômbia, onde a psicomotricidade foi vista como uma possibilidade de oferecer um novo estatuto epistemológico para a Educação Física (WILCHES, 2012), sua recepção no Brasil não assumiu esse caráter. Ao contrário, os pressupostos "de fundo" da abordagem psicomotricista ainda continham traços de uma tradição que precisaria ser superada na renovação pretendida no campo. 
se ao objeto de estudo da Educação Física como cultura corporal, cultura corporal de movimento ou cultura de movimento. A despeito de suas diferenças de "fundo", essas compreensões coincidem quanto à necessidade de ser a prática pedagógica a razão de ser da disciplina e a cultura ser sua referência fundante. Tais conceitos são, assim, sinônimos de uma Educação Física renovada.

O movimento crítico instalado na Colômbia e o debate epistemológico que provocou possibilitaram a construção de propostas teóricas alternativas à tradição da Educação Física colombiana, o que resultou em uma renovação discursiva que, especificamente a partir da década de 1990, teve uma consequência particularmente importante: uma "redescoberta do corpo" na área, caracterizada por uma nova maneira de teorizá-lo, basicamente desde o diálogo mais estreito com estudos das Ciências Sociais, Humanas e a Filosofia. Essa tendência é bastante evidente nas páginas das duas revistas estudadas a partir de diferentes conceitos e propostas, manifestando-se, além disso, nas vozes dos entrevistados. ${ }^{14}$

Semelhante processo aconteceu no Brasil, uma vez que, no país, também se produziu, inclusive à luz de referenciais teóricos similares aos observados na Colômbia, um questionamento do significado de corpo e de movimento pressuposto na tradição instaurada, em uma tentativa de romper com a visão biologicista-mecanicista do corpo, que sustentou sua compreensão como objeto, organismo, máquina, produto de um tipo de racionalidade que, com o imperativo da esportivização/cientifização, tornou hegemônico um entendimento reducionista de ciência.

Esta renovação no estatuto ontológico e/ou epistemológico do corpo, nos dois países, resultou, de um lado, em uma "virada culturalista" ao inserir, de uma vez por todas, o corpo na dinâmica da cultura, na dimensão simbólica, mas, de outro lado, produziu uma "virada corporalista" baseada na necessidade de "incorporar" as subjetividades, de "encarnar" os sujeitos. Essa "dupla virada" favoreceu a ideia de que a materialidade do corpo é construída culturalmente, mas, ao mesmo tempo, que a corporeidade cumpre um papel ativo na constituição das subjetividades e da própria cultura (vale dizer, da linguagem, portanto). A Educação Física, nos dois países, passou, assim, de "[...] uma imagem biológica do corpo a uma que o concebia como uma construção social ou discursiva [...]", mas, ao mesmo tempo, ganhou força a compreensão do corpo "[...] com potencial de ação que não se submete totalmente a uma determinada construção discursiva" e que pode "[...] servir de base para outros processos de subjetivação" (BRACHT, 2015, p. 3-4).

\section{CONSIDERAÇÕES FINAIS}

O objetivo deste artigo foi traçar, desde um ponto de vista comparado com o Brasil, afinidades, diferenças, rupturas e permanências em relação a uma experiência de crítica e renovação na Educação Física colombiana a partir das últimas décadas do século XX. Não deixa de surpreender, malgrado a distância geográfica, cultural e linguística, os traços comuns a respeito desse fenômeno nos dois países.

14 Uma expressão dessa redescoberta é a proposta do alemão Rittner (1995) de substituir a expressão "Ciência do Esporte" por "Cultura Somática", entendida como "[...] un sistema de valores y de normas relacionadas entre sí, en una sociedad dada, la cual implica la percepción y la utilización, o bien el uso del cuerpo en su totalidad". Ritter, com colegas colombianos, fundou, na Universidad de Antioquia, o grupo de pesquisa Cultura Somática. 
A análise evidenciou que os anos 1970 foram cruciais para a consolidação de uma tradição esportivista e cientificista da Educação Física de ambas as realidades, o que produziu muitas alterações de sentido na prática pedagógica do componente curricular. Nesse contexto, o acordo estabelecido com os alemães, baseado na necessidade de superar o déficit de cientificidade da Educação Física, contribuiu, no início, para a instauração de uma nova perspectiva, tanto no Brasil como na Colômbia.

Esta perspectiva cientificista levou, no Brasil, a um "incremento" da ciência (com mais oferta de mestrados e doutorados) que não tem paralelo, desse ponto de vista, na Educação Física colombiana. ${ }^{15}$ As razões dessas diferenças precisam ser explicadas, seguramente, considerando as políticas científicas de incentivo à pesquisa adotadas por Brasil e Colômbia desde as últimas décadas do século XX, o que extrapolaria, desse modo, a influência alemã e o próprio âmbito da Educação Física. ${ }^{16}$

Os resultados encontrados também mostraram que a esportivização e a cientifização, no Brasil e na Colômbia, não se deram sem tensões, dissensos e muito debate sobre os rumos mais apropriados para a relação entre a Educação Física, o esporte e a ciência. Tratou-se de um conflito de ideias com a participação dos alemães, dos estudantes, de professores escolares e acadêmicos, o qual se iniciou ainda nos anos 1960, mas que na década de 1980 foi marcado pela presença de um referencial teórico "crítico", com destaque, nos dois países, para a perspectiva marxista. ${ }^{17}$ Como consequência dessa crítica, que não se resumiu à influência marxista, produziu-se, nos respectivos campos, um debate a respeito da identidade epistemológica da disciplina, ocasião para que tendências internacionais de Educação Física impactassem nas reflexões dos dois países. A despeito das diferenças e semelhanças encontradas a esse respeito, os autores que alimentaram os esforços de "saída" da crise instaurada compartilhavam a preocupação de encontrar uma alternativa à tradição esportivista, bem como ao predomínio de uma compreensão reducionista de ciência que conquistou hegemonia nas duas nações. Isso possibilitou um questionamento do paradigma biomédico na área, criando as condições de possibilidade para uma virada cultural e corporalista que levou a uma renovação do status do corpo na Educação Física do Brasil e da Colômbia.

Quando comparada ao Brasil, a Colômbia ainda carece de mais estudos que deem visibilidade às mudanças paradigmáticas ocorridas na história recente do campo científico da Educação Física. Esse é um exercício importante, pois, além de permitir avaliar o alcance, os limites e as possibilidades produzidas pela crítica à tradição da área, possibilita, com a ajuda do passado, perspectivar um futuro renovado para a disciplina.

15 Como resultado, no Brasil existem, "hoje", 40 Mestrados e 22 Doutorados na área da Educação Física. Na Colômbia existem cursos de mestrado em várias universidades e está em vias de se iniciar o primeiro curso de Doutorado no âmbito do Instituto de Educación Física da Universidad de Antioquia.

16 Também se deve destacar o papel da intelectualidade alemã na construção de um pensamento crítico na Educação Física brasileira. É influenciado por eles, por exemplo, que Kunz (1991) elaborou sua perspectiva críticoemancipatória de Educação Física.

17 Não foram os acadêmicos alemães da Educação Física os responsáveis pela divulgação da leitura marxista na Educação Física, tanto no Brasil como na Colômbia. 


\section{REFERÊNCIAS}

ACEVEDO, Álvaro Tarazona; GONZÁLEZ, Diana Cruzelli. Movilización y protesta estudiantil en Colombia (1971): Una lectura desde la organización gremial por el cogobierno universitario y la memoria de protagonistas y testigos. Anuario de Historia Regional y de las Fronteras, v. 16, n. 1, p. 221-242, 2011.

ALMEIDA, Felipe Quintão; BRACHT, Valter; VAZ, Alexandre Fernandez Educação Física, pedagogia crítica e ideologia. Movimento, v. 21, n. 2, p. 317-331, 2015.

AMADIO, Antônio Carlos. Construindo o futuro, significado dos 40 anos da Pós-graduação da EEFE-USP e contextualização histórica: Universidade e ciência. Revista Brasileira de Educação Física e Esporte, v. 31, n. esp., p. 7-18, 2017.

BARDIN, Laurence. Análise de conteúdo. São Paulo: Edições 70, 2011.

BOLIVAR, Carlos. Formación curricular e identidad profesional del licenciado en Educación Física. Educación Física y Deporte, v. 10, n. 1-2, p. 9-21, 1988.

BOLÍVAR, Carlos. Educación Física: aproximación epistemológica. Educación Física y Deporte, v. 13, n. 1/2, p. 9-21, 1991.

BRACHT, Valter. Educação e Ciência: cenas de um casamento (in)feliz. ljuí: Unijuí, 1999.

BRACHT, Valter. Prólogo. In: FERREIRA, Adrián. (org.). Pensando la Educación Física como área del conocimiento: problematizaciones pedagógicas del sujeto y el cuerpo. Buenos Aires: Miño y Dávila, 2015. p. 1-7.

BRACHT, Valter et al. A Educação Física Escolar como tema da produção do conhecimento nos periódicos da área no Brasil (1980- 2010): parte I. Movimento, v. 17, n. 2, p. 11-34, 2011.

BRACHT, Valter et al. A Educação Física Escolar como tema da produção do conhecimento nos periódicos da área no Brasil (1980- 2010): parte II. Movimento, v. 18, n. 2, p. 11-37, 2012 ,

CHINCHILLA, Victor. Una reforma académico profesional que transforme la Educación Física. Educación Física y Deporte, v. 11, n. 1-2, p. 53-62, 1989.

COSTA, Lamartine Pereira. Diagnóstico de educação física/desportos no Brasil. Rio de Janeiro: Ministério da Educação e Cultura/Fundação Nacional de Material Escolar, 1971.

EDITORIAL. Revista Brasileira de Ciências do Esporte, v. 2, n. 2, p. 4, 1981.

EUSSE, Karen Lorena Gil. Tradição, crítica e renovação na Educação Física colombiana. 2020. Tese (Doutorado em Educação Física) - Programa de Pós-Graduação em Educação Física, Vitória, 2020.

EUSSE, Karen Lorena Gil; ALMEIDA, Felipe Quintão; BRACHT, Valter. Convênio ColomboAlemão (1973-1984): a esportivização da Educação Física colombiana? Revista da Alesde, 9, 106-118, 2018. DOI: http://dx.doi.org/10.5380/jlasss.v9i2.61272

EUSSE, Karen Lorena Gil; ALMEIDA, Felipe Quintão; BRACHT, Valter. "Esportivização" da Educação Física colombiana: a "herança" do convênio Colombo-Alemão nas páginas da revista Educación Física y Deporte. Revista Brasileira de Ciências do Esporte, v. 41, n. 4, p. 437-443, 2019a. 
EUSSE, Karen Lorena Gil; ALMEIDA, Felipe Quintão; BRACHT, Valter. Cientifização da Educação Física colombiana: a marca do Convênio Colombo-Alemão. In: GOMES, I. M., GALAK, E., ALMEIDA, F. Q Y MORENO, W. G. (Org.). Sentidos y prácticas sobre la educación y los usos del cuerpo: Intercambios académicos entre Argentina, Brasil, Colombia y Uruguay. La Plata/Vitória: Universidad de La Plata/Edufes. 2019b. p. 198-213.

FACULTAD Educación Física. En busca de los contenidos de la Educación Física. Lúdica Pedagógica, v. 1, n. 7, p. 1-6, 2002.

GALL, Hermann. Desarrollo y evaluación curricular de la educación física en Colombia. Educación Física y Deporte, v. 2, n. 2, p. 1-4, 1980.

HILDEBRANDT, Reiner; LAGING, Ralf. Concepções abertas no ensino da Educação Física. Rio de Janeiro: Ao Livro Técnico, 1986.

KUNZ, Elenor. Educação Física: ensino \& mudanças. ljuí: Unijuí, 1991.

MACHADO, Thiago da Silva. Sobre o impacto do movimento renovador da Educação Física nas identidades docentes. 2012. Dissertação (Mestrado em Educação Física) - Programa de Pós-Graduação em Educação Física da Universidade Federal do EspíritoSanto, Vitória, 2012.

MANOEL, Edison de Jesus; CARVALHO, Yara Maria de. Pós-graduação na educação física brasileira: a atração (fatal) para a biodinâmica. Educação e Pesquisa, v. 37, n. 2, p.389406, 2011.

OLIVEIRA, Marcus Aurélio Taborda. A Revista Brasileira de Educação Física e Desportos (1968-1984) e a experiência de professores da rede municipal de ensino de Curitiba: entre a adesão e a resistência. 2001. 399 f. Tese (Doutorado em Educação: História e Filosofia da Educação) - Programa de Estudos Pós-graduados em Educação, Pontifícia Universidade Católica, São Paulo, 2001.

PAIVA, Fernanda Simone Lopes. Ciência e poder simbólico no Colégio Brasileiro de Ciências do Esporte. Vitória: CEFD/UFES, 1994.

PINILLOS, José Maria. La Educación Física y el deporte en Colombia. Una oposición de discursos en el periodo comprendido entre 1968 y 1991. 2003. Tesis (Maestría) - Universidad de Antioquia, Facultad de Educación, Medellín, 2003. Disponível em: http://ayura.udea.edu. co:8080/jspui/bitstream/123456789/561/1/AA0260.pdf. Acesso em: 14 dez. 2020.

RITTNER, Volka. Cuerpo, salud, deporte y estilo de vida como puntos de referencia del desarrollo social. Revista Educación Física y Deporte, v. 17, n. 1, p. 63-77, 1995.

ROSA, Juliano de Melo. O CEFD/UFSM na atribuição de sentidos à Educação Física escolar entre 1970 e 2004. 2017. Dissertação (Mestrado em Educação) - Programa de Pós-Graduação em Educação da Universidade Federal de Santa Maria, Santa Maria, 2017.

SANTOS, Fernanda Cristina. Bola em jogo entre Brasil e República Federal da Alemanha: cientificidade e modelagem pedagógica na formação de professores na Escola de Educação Física da UFMG (1963-1982). 2017. Dissertação (Mestrado em Educação) Programa de Pós-Graduação em Educação da Universidade Federal de Minas Gerais, Belo Horizonte, 2017.

URREGO, León Jaime. Estudio de la producción de conocimiento en la Educación Física en Colombia entre 1990 y 2006. 2014. Tese (Doctorado em Educación y Trabajo Social) - Departamento de Didáctica de la Expresión Musical, Plástica y Corporal de la Universidad de Valladolid, España, 2014. 
VACA, Angel Humberto $\mathrm{H}$. Historia del alma máter de la Educación Física colombiana. Santa Fe de Bogotá: Universidad Pedagógica Nacional, 1998.

WILCHES, Daniel. Ideas influyentes en la teoría de la Educación Física de la Facultad de Educación Física de la Universidad Pedagógica Nacional (Bogotá) entre 1975 y 2000. 2012. Tese (Doctorado em Ciencias de la Actividad Física y el Deporte) Departamento de Educación Física y Deportes da Universidad de León, León-España, 2012. 
Abstract: This article analyzes a movement towards critique and reinvention of Colombian Physical Education started in 1970s, comparing it with a similar phenomenon in Brazil. In methodological terms, on the one hand, the investigation is carried out through content analysis of papers published in two Colombian journals and 16 interviews with professionals of Physical Education from Colombia; on the other hand, the study is based on numerous articles on the theme in Brazil. The comparative examination shows distinct consequences regarding 'sportivization' and 'scientificization' and their impacts on Physical Education, which enables us to identify not only similarities, differences and ruptures, but also epistemological reinventions produced in Physical Education in both countries.

Keywords: Sports. Science. Brazil. Colombia.

Resumen: Este artículo analiza un movimiento de crítica y renovación de la Educación Física colombiana a partir de las últimas décadas del siglo XX, comparándolo con fenómeno similar en Brasil. Metodológicamente, está fundamentado, por un lado, en el análisis de contenido de dos revistas colombianas y en 16 entrevistas con profesionales de la Educación Física de ese país. Por otro lado, se basa en la abundante literatura dedicada al tema en Brasil. La reflexión comparada demuestra las diversas consecuencias del proceso de deportivización y cientifización del componente curricular, oportunidad para identificar semejanzas, diferencias, continuidades y rupturas, pero también las renovaciones epistemológicas producidas en la Educación Física de los dos países.

Palabras clave: Deportes. Ciencia. Brasil. Colombia. 


\section{LICENÇA DE USO}

Este é um artigo publicado em acesso aberto (Open Access) sob a licença Creative Commons Atribuição 4.0 Internacional (CC BY 4.0), que permite uso, distribuição e reprodução em qualquer meio, desde que o trabalho original seja corretamente citado. Mais informações em: http://creativecommons.org/licenses/by/4.0

\section{CONFLITO DE INTERESSES}

Os autores declararam que não há conflito de interesses neste trabalho.

\section{CONTRIBUIÇÕES AUTORAIS}

Karen Lorena Gil Eusse: escrita do artigo e autora da tese de doutorado em que se baseou este artigo.

Felipe Quintão de Almeida: escrita e supervisão.

Valter Bracht: escrita e orientação.

\section{FINANCIAMENTO}

O presente trabalho foi realizado com auxílio de bolsa de doutorado concedida pela Fundação de apoio à Pesquisa do Estado do Espírito Santo (FAPES).

\section{ÉTICA EM PESQUISA}

O projeto foi submetido no comitê de humanidade da Universidade Federal do Espírito Santo (UFES), registrado sob o número 0545881820000552 e o parecer de aprovação teve o número 344294. Na pesquisa que dá origem a este artigo, realizamos, além do estudo de periódicos dos dois países, entrevistas com docentes colombianos que participaram, de distintas maneiras, da crítica e renovação da Educação Física naquele país.

\section{COMO REFERENCIAR}

EUSSE, Karen Lorena Gil; ALMEIDA, Felipe Quintão; BRACHT, Valter. Crítica e renovação da educação física colombiana: uma comparação com Brasil. Movimento (Porto Alegre), v.27, p. e27009, jan./dez. 2021. Disponível em: https:// seer.ufrgs.br/Movimento/article/view/105572. Acesso em: [dia] [mês abreviado]. [ano]. DOI: https://doi.org/10.22456/1982-8918.105572

\section{RESPONSABILIBADE EDITORIAL}

Alex Branco Fraga*, Elisandro Schultz Wittizorecki, Ivone Job*, Mauro Myskiw*, Raquel da Silveira*

*Universidade Federal do Rio Grande do Sul, Escola de Educação Física, Fisioterapia e Dança, Porto Alegre, RS, Brasil 